\title{
Pollen food allergy syndrome in Turkey: Clinical characteristics and evaluation of its association with skin test reactivity to pollens
}

\author{
Seçil Kepil Özdemir, ${ }^{1}$ Selcan Özgüçlü ${ }^{1}$
}

\begin{abstract}
Background: There is limited data regarding pollen food allergy syndrome (PFAS) in Turkey.

Objectives: To investigate the clinical characteristics and possible risk factors of PFAS in Turkey, and to evaluate if there was an association between skin test reactivity to pollens and presence of PFAS.

Methods: A total of 254 consecutive adult patients with pollen sensitivity were prospectively recruited. Patients were interviewed with a questionnaire including a list of pollen-associated foods. Patients were classified as having PFAS if they reported clear allergic symptoms compatible with PFAS. All participants underwent skin prick tests (SPT) to a panel of common aeroallergens, prick-to-prick tests with culprit fresh foods were performed in patients who gave consent.

Results: Self-reported PFAS was observed in 49 patients (19.3\%). The most common culprit foods were kiwi, peach, tomato, melon and watermelon. Multiple logistic regression analysis showed that potential risk factors for PFAS were having asthma $(\mathrm{OR}=2.392, P=0.044)$ and tree pollen sensitization $(\mathrm{OR}=2.904, P=0.004)$. There were no significant differences in the SPT wheal sizes to individual pollen extracts between patients with and without PFAS with a positive SPT result for that pollen extract $(P>0.05)$.
\end{abstract}

Conclusions: PFAS is frequent in pollen sensitized adults in Turkey. The most commonly implicated foods are kiwi, peach,tomato, melon and watermelon, in our geographical region. SPT wheal sizes to pollen extracts seems to be similar in patients with and without PFAS.

Keywords: Grass pollen, oral allergy syndrome, pollen allergy, pollen food allergy syndrome, skin prick tests.

\section{From:}

Dışkapı Yıldırım Beyazıt Training and Research Hospital, Division of Allergy and Immunology, Ankara, Turkey.

\section{Introduction}

Pollen food allergy syndrome (PFAS) is an immunoglobulin $\mathrm{E}$ (IgE) mediated disease, with sensitizing reactions occurring between IgE antibodies and cross-reactive pollen allergens. The IgE originally generated in response to pollen exposure will also bind to food proteins, and producing the symptoms of PFAS. ${ }^{1}$ Regional differences in pollen distribution and dietary habits influence the prevalence and implicated foods in PFAS. Most studies on PFAS have focused on patients with birch pollen allergy. In northern and central Europe, apple and hazelnut are most commonly implicated foods because of birch pollen sensitization while in Japan reactions to apple and

\section{Corresponding author:}

Seçil Kepil Özdemir

Izmir Dr. Suat Seren Gogus Hastallkları ve Cerrahisi Egitim ve

Arastirma Hastanesi, Allerji ve İmmunoloji Birimi, Izmir (TURKEY)

E-mail: secilkepil@gmail.com

peach are more common in correlation with sensitization to alder. ${ }^{2,3,4}$ Contrary to the common birch pollen sensitization in central and northern Europe, grass allergy is the most common cause of pollinosis and tree allergy is relatively rare compared with grass and weed sensitization in Turkey, a Mediterranean area country. ${ }^{5}$ There is limited data regarding PFAS from southeastern Europe and Turkey. Additionally, grass pollen and food cross reactivity is not as well described as tree pollen or weed pollen related PFAS. The primary objective of this study was to determine the frequency and clinical characteristics of self-reported PFAS in pollen-sensitized 
adults in our geographical region which is located in central Anatolia. The secondary objectives were to investigate the possible risk factors for the development of PFAS and to evaluate if there was an association between skin test reactivity to pollens and presence of PFAS.

\section{Methods \\ Study population}

Two hundred fifty-four consecutive adult patients with pollen sensitivity in skin prick tests were prospectively recruited between April - August 2016. Criteria for eligibility were as follows: (a) age $\geq 18$ years; (b) positive skin prick test result with a pollen extract. The study was approved by the Local Ethics Committee of the study center and written informed consent was obtained from all subjects.

All patients were interviewed by allergists with a questionnaire including a list of 38 pollen-associated foods (almond, apple, apricot, banana, black pepper, broccoli, cabbage, caraway, carrot, cauliflower, celery, chard, cherry, chickpea, coriander, cucumber, cummin, fennel, garlic, green beans, hazelnut, kiwi, lettuce, melon, mustard, onion, orange, parsley, peach, peanut, pear, pepper, plum, potato, soybean, tomato, watermelon, and zucchini). Patients were classified as having PFAS if they reported clear allergic symptoms compatible with PFAS (symptoms of oral allergy syndrome such as itching/edema of the oral mucosa) shortly $(\leq 10$ minutes) after consumption of typical pollen-associated foods. Additionally, demographic data, history of atopic disease, clinical features of the concomitant allergic disease(s), relevant medical history were recorded. The severity of the symptoms related to the primary allergic disease was assessed with visual analogue scale.

\section{Skin prick tests}

All of the participants underwent skin prick tests (SPTs) to a standard panel of common aeroallergens including grasses (Dactylis glomerata, Lolium perenne, Phleum pretense, Poa pratensis, Anthoxanthum odaratum), Artemisia vulgaris, Plantago, Parieteria officinalis, Betulaceae (Alnus glutinosa, Betula alba, Carpinus betulus, Corylus avellana), Fagaceae (Castanea vulgaris, Quercus robur, Fagus sylvatica), house dust mites (Dermatophagoides farinae and Dermatophagoides pteronyssinus), Blatella germenica, Alternaria alternata, Cladosporium mix (Cladosporium cladosporioides, C. herbarum), cat dander, along with positive (histamine $10 \mathrm{mg} / \mathrm{ml}$ ) and negative control (Stallergenes, France). Prick-to-prick tests with culprit fresh foods were recommended for all patients with PFAS, and these tests were performed in patients who gave consent. Skin prick tests were performed on the volar forearm, and were read after 20 minutes. A wheal reaction with a mean diameter of 3 $\mathrm{mm}$ greater than the negative control was considered positive.

\section{Statistical Analysis}

The statistical analysis was performed using the SPSS program version 18.0 (SPSS Inc., Chicago, IL, USA). Shapiro -Wilk test was used to evaluate the distribution of quantitative data. If the data were normally distributed Student's t-test or otherwise Mann-Whitney test was performed for comparisons for quantitative variables. Chi-square test was used to compare qualitative variables. Multiple logistic regression analysis was performed to identify significant risk factors for PFAS. We used forward stepwise selection and a full model analysis that included the variables gender, familial history of atopic disease, presence of allergic comorbidities, sensitization to grass pollens, sensitization to weed pollens, sensitization to tree pollens, polysensitization, multiple pollen sensitization, age, duration of the primary allergic disease since onset, visual analogue scale scores related to the primary allergic disease. A p-value of $<0.05$ was considered significant.

\section{Results \\ Subject characteristics}

A total of 254 patients, i.e. 154 females (60.6\%) and 100 males (39.4\%); median (min.-max.) age 27 (18-68) years were included in the study. The vast majority $(248 / 254,97.6 \%)$ of the patients had allergic rhinitis, 30 patients $(11.8 \%)$ had asthma, 17 (6.7\%) had urticaria, 6 (2.4\%) had atopic dermatitis and $1(0.4 \%)$ had anaphylaxis. Sixty-six $(26.0 \%)$ patients had more than one allergic disease. The mean $( \pm \mathrm{SD})$ allergic disease duration since onset was $6.8( \pm 5.6)$ years.

The vast majority of the patients were sensitized to grass pollens (243 patients, 95.7\%). Sensitization to weed pollens was detected in 126 patients (49.6\%). Sensitization to tree pollens was detected in 46 patients (18.1\%). Overall, 130 patients $(51.2$ $\%)$ had multiple pollen sensitization to grasses, weeds and/or trees. One hundred-fourteen patients had isolated grass pollen allergy, 8 patients had isolated weed pollen sensitization and 2 patients had isolated tree pollen sensitization. Eighty-two patients $(32.3 \%)$ had another aeroallergen sensitization in addition to pollen sensitization.

\section{Characteristics of PFAS}

Self-reported PFAS was observed in 49 patients (19.3\%). Clinical characteristics of the patients with and without a history of PFAS are shown in Table 1. Symptoms were restricted to oropharynx in $45(91.8 \%)$ patients, 4 patients $(8.2 \%)$ had concurrent systemic symptoms and 1 patient $(0.5 \%)$ had anaphylaxis. The most common culprit foods were kiwi, peach, tomato, melon and watermelon (Table 2). Kiwi fruit and tomato were also the most common causative foods in patients with isolated grass pollen sensitization and PFAS (10/18, $55.6 \% ; 5 / 1827.8 \%$, respectively). The majority of the patients with PFAS (30/49 patients, 61.2\%) exhibited symptoms to more than one food. In the only patient with a history of anaphylaxis, the culprit food was celery and the patient had positivity on skin prick tests with mugwort and celery. Seasonal increase of PFAS symptoms during the pollen season was reported in $5 / 49$ patients $(10.2 \%)$. Two patients $(2 / 49,4.1 \%)$ reported that peeling off the culprit food caused a decrement of the symptoms.

Diagnostic prick-to-prick tests with culprit fresh foods were performed in $16 / 49$ patients and positivity on prick-to-prick tests was detected in $10 / 16$ patients $(62.5 \%)$. 
Table 1. Comparison of the characteristics of the patients with and without pollen food allergy syndrome.

\begin{tabular}{|c|c|c|c|}
\hline Characteristic & PFAS (+) & PFAS (-) & $P$ value \\
\hline N (\%) & $\begin{array}{l}49 / 254 \\
(19.3 \%)\end{array}$ & $\begin{array}{l}205 / 254 \\
(80.7 \%)\end{array}$ & - \\
\hline $\begin{array}{l}\text { Age, median }(\min -\max ) \text {, } \\
\text { years }\end{array}$ & $25(18-68)$ & $28(18-62)$ & 0.381 \\
\hline Gender (F/M) & $35 / 14$ & $119 / 86$ & 0.085 \\
\hline $\begin{array}{l}\text { Presence of familial } \\
\text { history of atopy, } n(\%)\end{array}$ & $32(65.3 \%)$ & $94(45.9 \%)$ & $0.014^{\star}$ \\
\hline \multicolumn{4}{|l|}{$\begin{array}{l}\text { Allergic comorbidities, } \\
\mathrm{n}(\%)\end{array}$} \\
\hline Allergic rhinitis & 47 (95.9\%) & $201(98.0 \%)$ & 0.327 \\
\hline Asthma & $11(22.4 \%)$ & $19(9.3 \%)$ & $0.010^{\star}$ \\
\hline Atopic dermatitis & $2(4.1 \%)$ & $4(2.0 \%)$ & 0.327 \\
\hline Drug allergy & $5(10.2 \%)$ & $7(3.4 \%)$ & 0.059 \\
\hline Food allergy & $3(6.1 \%)$ & $8(3.9 \%)$ & 0.448 \\
\hline Urticaria & $4(8.2 \%)$ & $13(6.3 \%)$ & 0.749 \\
\hline $\begin{array}{l}\text { VAS scores related to the } \\
\text { primary allergic disease, } \\
\text { median (min - max) }\end{array}$ & $8(1-10)$ & $8(1-10)$ & 0.284 \\
\hline $\begin{array}{l}\text { Duration of the allergic } \\
\text { disease since onset, } \\
\text { median (min - max), years }\end{array}$ & $6.0(1-25)$ & $4.5(0.1-27)$ & 0.057 \\
\hline \multicolumn{4}{|l|}{ Pollen sensitization, $n$ (\%) } \\
\hline Grass pollens & $48(98.0 \%)$ & $195(95.1 \%)$ & 0.696 \\
\hline Weed pollens & $25(51.0 \%)$ & $101(49.3 \%)$ & 0.826 \\
\hline Tree pollens & $17(34.7 \%)$ & $29(14.1 \%)$ & $0.001^{*}$ \\
\hline
\end{tabular}

VAS: Visual analogue scale, PFAS: Pollen food allergy syndrome, *statistically significant.

\section{Risk factors of PFAS}

There were no significant differences in age, gender, duration of the primary allergic disease since onset, visual analogue scale scores related to the primary allergic disease between the patients with and without PFAS (Table 1). Familial history of atopic disease was more frequent in patients with PFAS (65.3\% vs. $45.9 \%, P=0.014)$. Regarding allergic comorbidities, frequency of allergic rhinitis, atopic dermatitis, drug allergy, food allergy, and urticaria were similar in patients with and without PFAS (Table 1). However, patients with PFAS were more frequently affected by asthma (22.4\% vs. $9.3 \%, P=0.01)$. Additionally, sensitization rates to tree pollens were higher in patients with PFAS (34.7\% vs. $14.1 \%, P=0.001)$. Sensitization rates to grass pollens and weed pollens were not different statistically between the two groups (Table 1). PFAS was diagnosed in $17 / 46,37.0 \%$ of the patients sensitized to tree pollens. The rates of PFAS in patients with grass pollen sensitization and weed pollen sensitization were 48/243 (19.8\%), 25/126 (19.8\%), respectively. The rate of PFAS was 18/114 (15.8\%) in patients with isolated grass pollen sensitization. Rates of polysensitization and multiple pollen sensitization to grasses, weeds and/or trees were also statistically similar in patients with and without PFAS (38.8\% vs. $30.7 \%$, respectively, $\mathrm{p}$ value $=0.279$ for polysensitization; $61.2 \%$ vs. $48.8 \%$, respectively, $\mathrm{p}$ value $=0.117$ for multiple pollen sensitization). Multiple logistic regression analysis
Table 2. Culprit foods triggering symptoms in patients with pollen food allergy syndrome.

\begin{tabular}{|c|c|c|c|c|}
\hline \multirow[t]{2}{*}{ Culprit food } & \multicolumn{4}{|c|}{ Patients with PFAS } \\
\hline & $\begin{array}{l}\text { SPT }^{\star} \\
\text { positive, } \\
\text { n }\end{array}$ & $\begin{array}{l}\text { SPT }^{*} \\
\text { negative, } \\
\text { n }\end{array}$ & $\begin{array}{l}\text { SPT* not } \\
\text { performed, } \\
\text { n }\end{array}$ & $\begin{array}{l}\text { Overall, } \\
\text { n (\%) }\end{array}$ \\
\hline Kiwi & 0 & 3 & 16 & $19(38.8 \%)$ \\
\hline Peach & 5 & 1 & 11 & $17(34.7 \%)$ \\
\hline Tomato & 4 & 0 & 8 & $12(24.5 \%)$ \\
\hline Melon & 2 & 0 & 7 & $9(18.4 \%)$ \\
\hline Watermelon & 4 & 0 & 4 & $8(16.3 \%)$ \\
\hline Plum & 4 & 0 & 3 & $7(14.3 \%)$ \\
\hline Apricot & 3 & 0 & 3 & $6(12.2 \%)$ \\
\hline Hazelnut & 2 & 1 & 1 & $4(8.2 \%)$ \\
\hline Cucumber & 1 & 0 & 2 & $3(6.1 \%)$ \\
\hline Orange & 0 & 1 & 2 & $3(6.1 \%)$ \\
\hline Cherry & 3 & 0 & 0 & $3(6.1 \%)$ \\
\hline Banana & 1 & 0 & 2 & $3(6.1 \%)$ \\
\hline Black pepper & 0 & 1 & 1 & $2(4.1 \%)$ \\
\hline Sunflower seed & 2 & 0 & 0 & $2(4.1 \%)$ \\
\hline Onion & 0 & 1 & 0 & $1(2.0 \%)$ \\
\hline Zucchini & 0 & 1 & 0 & $1(2.0 \%)$ \\
\hline Celery & 1 & 0 & 0 & $1(2.0 \%)$ \\
\hline Almond & 0 & 0 & 1 & $1(2.0 \%)$ \\
\hline Apple & 0 & 0 & 1 & $1(2.0 \%)$ \\
\hline Caraway & 0 & 1 & 0 & $1(2.0 \%)$ \\
\hline Dill & 0 & 0 & 1 & $1(2.0 \%)$ \\
\hline
\end{tabular}

PFAS: Pollen food allergy syndrome, SPT: Skin prick test, ${ }^{*}$ Skin prick test with the culprit food.

of clinical features of the patients are shown in Table 3. Multiple logistic regression analysis with forward stepwise selection showed that potential risk factors for PFAS were having asthma $(\mathrm{OR}=2.392, \mathrm{p}$ value $=0.044)$ and tree pollen sensitization $(\mathrm{OR}=2.904$, $\mathrm{p}$ value $=0.004)($ Table 3$)$.

We investigated the association between SPT result sizes to individual pollen extracts and PFAS. While comparing SPT wheal sizes to individual pollen extracts in patients with and without PFAS, we analyzed results of the patients with a positive SPT result for that specific pollen extract. Among the 243 patients sensitized to grass pollens, the SPT wheal sizes to grass pollens were similar between patients with and without PFAS ( $\mathrm{p}=0.427$ ). Among the 31 patients sensitized to Betulaceae, the SPT result sizes to Betulaceae were similar between the two groups $(\mathrm{p}=0.847)$. Additionally, there were no significant differences in the SPT result sizes to other pollen extracts between patients with and without PFAS (Table 4). 
Table 3. Results of multiple logistic regression analysis to identify factors possibly associated with the presence of pollen food allergy syndrome.

\begin{tabular}{|c|c|c|c|c|c|c|}
\hline \multirow{2}{*}{$\begin{array}{l}\text { Full model } \\
\text { Variable }\end{array}$} & \multirow[b]{2}{*}{$P$ value } & \multirow[b]{2}{*}{ Odds ratio } & \multirow[b]{2}{*}{$95 \% \mathrm{CI}$} & \multicolumn{3}{|c|}{ Forward stepwise } \\
\hline & & & & $P$ value & Odds ratio & $95 \% \mathrm{CI}$ \\
\hline Gender & 0.087 & 1.898 & $0.910-3.958$ & - & - & - \\
\hline Asthma & 0.190 & 1.933 & $0.721-5.181$ & $0.044^{*}$ & 2.392 & $1.024-5.590$ \\
\hline Drug allergy & 0.250 & 2.197 & $0.574-8.409$ & - & - & - \\
\hline Urticaria & 0.318 & 1.948 & $0.526-7.214$ & - & - & - \\
\hline Food allergy & 0.583 & 1.538 & $0.331-7.159$ & - & - & - \\
\hline Polysensitization & 0.481 & 1.293 & $0.633-2.643$ & - & - & - \\
\hline Grass pollen sensitization & 0.366 & 3.225 & $0.255-40.748$ & - & - & - \\
\hline Weed pollen sensitization & 0.625 & 0.698 & $0.165-2.949$ & - & - & - \\
\hline Tree pollen sensitization & 0.060 & 2.710 & $0.958-7.667$ & $0.004^{*}$ & 2.904 & 1.412-5.972 \\
\hline Familial history of atopy & 0.202 & 1.607 & $0.775-3.333$ & - & - & - \\
\hline Multiple pollen sensitization & 0.768 & 1.283 & $0.245-6.723$ & - & - & - \\
\hline Age & 0.258 & 0.979 & $0.943-1.016$ & - & - & - \\
\hline VAS scores related to the primary allergic disease & 0.999 & 1.000 & $0.824-1.214$ & - & - & - \\
\hline Duration of the allergic disease since onset & 0.278 & 1.037 & $0.971-1.106$ & - & - & - \\
\hline
\end{tabular}

VAS: Visual analogue scale, ${ }^{*}$ statistically significant.

Table 4. Comparison of the skin prick test wheal diameters to individual pollen extracts in patients with and without pollen food allergy syndrome.

\begin{tabular}{|c|c|c|c|}
\hline $\begin{array}{l}\text { Pollen SPT wheal } \\
\text { size, median } \mathrm{mm} \text {, } \\
(\min -\max )\end{array}$ & PFAS (+) & PFAS (-) & $P$ value \\
\hline $\begin{array}{l}\text { Grass pollen } \\
\text { mixture }(n=243)\end{array}$ & $9.25(3.00-21.00)$ & $9.50(3.00-22.00)$ & $0.427^{\star}$ \\
\hline $\begin{array}{l}\text { Artemisia vulgaris } \\
(\mathrm{n}=82)\end{array}$ & $5.00(3.00-12.50)$ & $5.00(3.00-16.00)$ & $0.180^{*}$ \\
\hline Plantago $(n=63)$ & $5.75(3.00-10.00)$ & $5.00(3.00-10.00)$ & $0.289^{*}$ \\
\hline $\begin{array}{l}\text { Parieteria } \\
\text { officinalis }(\mathbf{n}=7)\end{array}$ & $3.75(3.00-4.50)$ & $8.00(3.00-9.50)$ & $0.113^{\star *}$ \\
\hline Betulaceae $(\mathrm{n}=31)$ & $5.00(3.00-8.00)$ & $5.00(3.00-9.00)$ & $0.847^{\star *}$ \\
\hline Fagaceae $(\mathrm{n}=26)$ & $4.50(3.00-7.00)$ & $4.00(3.00-9.00)$ & $0.836^{*}$ \\
\hline
\end{tabular}

SPT: Skin prick test, PFAS: Pollen food allergy syndrome, ${ }^{*}$ with Mann-Whitney U test, ${ }^{* *}$ with Student's t-test.

\section{Discussion}

In this study, we examined 254 subjects with pollen allergy from Turkey, and reported the clinical characteristics of self-reported PFAS in 49 of the patients in this sample, and compared the characteristics of the patients with and without PFAS. In our population, in which $95.7 \%$ were sensitized to grass pollens, $49.6 \%$ to weeds and $18.1 \%$ to tree pollens, the frequency of self-reported PFAS was $19.3 \%$. Sensitization to tree pollens was associated with the highest rates of PFAS (the frequency of PFAS was 37.0\%, 19.8\% and 19.8\% in tree, weed and grass pollen sensitization, respectively). Additionally, the result from the multiple logistic regression analysis showed that sensitization to tree pollens and presence of asthma were risk factors for PFAS. Although familial history of atopic diseases was more common in patients with PFAS, it was not a significant risk factor when it was adjusted with other associated factors in the multiple logistic regression analysis. Osterballe et al. reported that the highest probability of a clinical reaction after intake of relevant pollen-related foods was found in adults polysensitized to birch, grass and mugwort pollen and having symptoms in the pollen season. ${ }^{6}$ Additionally, they reported that sensitization to birch pollen was associated with a higher rate of PFAS than sensitization to weed or grass pollen, ${ }^{6}$ similar to the results in our study. The significant association between asthma and PFAS has also been reported in previous studies. $^{7-9}$ Our data, showed no differences in age, gender, duration of the pollen-related primary allergic disease, between the patients with and without PFAS. Contrary to this result, two previous studies reported longer durations of allergic rhinitis in patients with PFAS. ${ }^{89}$ However, another large study found no significant difference in the duration of birch pollen allergy in patients with and without PFAS. ${ }^{10}$

Because of the regional differences in pollen distribution, the prevalence and implicated foods vary between different geographical regions. Based on our data, the main causative foods in PFAS were kiwi, peach, tomato, melon and watermelon in our country. To the best of our knowledge, there is only one published study about oral allergy syndrome in Turkey, however, implicated foods have not been reported in that study.

Grass pollen and food cross reactivity is not as well described as tree or weed pollen related PFAS. In this study, the 
rate of PFAS was 15.8\% and the main causative foods were kiwi and tomato in patients with isolated grass pollen sensitization. Symptoms to cross-reacting foods were reported in $4 \%-19 \%$ of the subjects sensitized to grass pollens in previous studies. ${ }^{6,11}$ Sensitization profiles to different allergen components may be responsible for the variable frequencies of PFAS in grass pollen sensitization reported from different geographical regions. In the recent multicenter study of Mastrorilli et al, which is performed in Italy, in another Mediterranean country, kiwi fruit was also the food that is most commonly triggering PFAS. ${ }^{8}$ Another large study performed in Italy, also reported kiwi fruit to be the most frequently reported plant-derived food to be a cause of allergic reactions. ${ }^{12}$ Allergic reactions to kiwi have been reported in association with birch and grass pollen allergies. ${ }^{12,13,14}$ Furthermore, it has been shown that kiwi fruit contains a large number of allergens widely cross-reacting with allergens in grass and birch pollen extracts. ${ }^{13}$

Because of the high number of patients included in this study, we could investigate the association between SPT wheal sizes to individual pollen extracts and PFAS, by analyzing results of the patients with a positive SPT result for the examined pollen extract. There were no significant differences in the SPT wheal sizes to the pollen extracts between patients with and without PFAS. Our findings in this respect differ from those of Ta et al, who described significantly larger sized SPT results of all the pollens combined (birch, mugwort, ragweed, tree, weed, grass mixes). ${ }^{15}$ This discrepancy might be related to the use of different parameters while comparing SPT result sizes. Whereas, Ta et al used combined SPT results of all the pollens, we used SPT wheal sizes to individual pollen extracts of the patients with a positive SPT result for the examined pollen extract, separately. Although not confirmed in our study, patients with sensitization to multiple pollens have been shown to be more likely affected by PFAS. ${ }^{6,9,11}$ Therefore, the larger sized SPT results of all the pollens combined in patients with PFAS compared to patients without PFAS may reflect the increased risk of PFAS in pollen-polysensitization.

In this study, we used questionnaire based interviews performed by allergists to diagnose PFAS. A major limitation of our study is that we did not perform double-blind, placebo-controlled challenges with the culprit foods to confirm the diagnosis of PFAS. However, allergic symptoms in PFAS immediately follow food ingestion and therefore they are easily recognized by the patients. It is previously shown that a positive clinical history has a high positive predictive value, ${ }^{16}$ and a questionnaire-based diagnosis of PFAS also yielded a high positive predictive value compared to those of a protocol combining clinical history, and food challenges. ${ }^{17}$ Additionally, because of the lability of allergens in fresh fruits, and difficulty of ensuring oral contact with adequate concentrations of the culprit food in a masking solution cause difficulty in performing double-blind, placebo-controlled challenges in PFAS. ${ }^{18}$ Another limitation of this study is the low rate of performing diagnostic prick-to-prick tests with the culprit foods. This limitation mainly resulted from the difficulty to access the culprit fresh foods at the clinic during the first appointment. Generally, we had to ask the patient for a second appointment to obtain the culprit fresh foods, and this reduced the compliance and the proportion of the patients tested. In conclusion, self-reported
PFAS is frequent in pollen sensitized adults in Turkey, which is located in the eastern Mediterranean region, and sensitization to tree pollens is associated with the highest rates of PFAS. Additionally, a significant proportion of the patients with isolated grass pollen sensitivity reports PFAS. The most commonly implicated foods in patients with PFAS are kiwi, peach, tomato, melon and watermelon, in our geographical region. SPT wheal sizes to individual pollen extracts seem to be similar in patients with and without a history of PFAS.

\section{Acknowledgements}

The authors would like to thank nurse Gülşan Taşkıran Apaydin for her help during the skin prick tests.

\section{Conflict of Interests}

The authors have no conflict of interest to declare.

\section{References}

1. Ludman S, Jafari-Mamaghani M, Ebling R, Fox AT, Lack G, Du Toit G. Pollen food syndrome amongst children with seasonal allergic rhinitis attending allergy clinic. Pediatr Allergy Immunol. 2016; 27: 134-40.

2. Geroldinger-Simic M, Zelniker T, Aberer W, Ebner C, Egger C, Greiderer A, et al. Birch-pollen related food allergy: clinical aspects and the role of allergen-specific IgE and IgG4 antibodies. J Allergy Clin Immunol. 2011; 127:616-22.

3. Maeda N, Inomata N, Morita A, Kirino M, Ikezawa Z. Correlation of oral allergy syndrome due to plant-derived foods with pollen sensitization in Japan. Ann Allergy Asthma Immunol. 2010; 104: 205-10.

4. Brown CEB, Katelaris $\mathrm{CH}$. The prevalence of the oral allergy syndrome and pollen-food syndrome in an atopic paediatric population in south-west Sydney. J Paediatr Child Health. 2014; 50: 795-800.

5. Buyuktiryaki B, Cavkaytar O, Sahiner UM, Yilmaz EA, Yavuz ST, Soyer O, et al. Cor a 14, Hazelnut-specific IgE, and SPT as a reliable tool in hazelnut allergy diagnosis in eastern Mediterranean children. J Allergy Clin Immunol Pract. 2016; 4: 265-72.

6. Osterballe M, Hansen TK, Mortz CG, Bindslev-Jensen C. The clinical relevance of sensitization to pollen-related fruits and vegetables in unselected pollen-sensitized adults. Allergy. 2005; 60: 218-25.

7. Caliskaner Z, Naiboglu B, Kutlu A, Kartal O, Ozturk S, Onem Y, et al. Risk factors for oral allergy syndrome in patients with seasonal allergic rhinitis. Med Oral Patol Oral Cir Bucal. 2011; 16: e312-6.

8. Mastrorilli C, Tripodi S, Cafferelli C, Perna S, Di Rienzo-Businco A, Sfika I, et al. Endotypes of pollen-food syndrome in children with seasonal allergic rhinoconjunctivitis: a molecular classification. Allergy. 2016; 71: 1181-91.

9. Asero R, Massironi F, Velati C. Detection of prognostic factors for oral allergy syndrome in patients with birch pollen hypersensitivity. J Allergy Clin Immunol. 1996; 97: 611-6.

10. Asero R. Relevance of pollen-specific IgE levels to the development of Apiaceae hypersensitivity in patients with birch pollen allergy. Allergy 1997;52:560-4.

11. Ghunaim N, Grönlund H, Kronqvist M, Grönneberg R, Söderström L, Ahlstedt S, et al. Antibody profiles and self-reported symptoms to pollen-related food allergens in grass pollen-allergic patients from northern Europe. Allergy. 2005; 60: 185-91.

12. Dondi A, Tripodi S, Panetta V, Asero R, Di Rienzo Businco A, Bianchi A, et al. Pollen-induced allergic rhinitis in 1360 Italian children: Comorbidities and determinants of severity. Pediatr Allergy Immunol. 2013; 24: 742-51.

13. Pastorello EA, Pravettoni V, Ispano M, Farioli L, Ansaloni R, Rotondo F, et al. Identification of the allergenic components kiwi fruit and evaluation of their cross-reactivity with timothy and birch pollens. J Allergy Clin Immunol. 1996; 98: 601-10.

14. Gall H, Kalveram KJ, Fork G, Sterry W. Kiwi fruit allergy: a new birch pollen-associated food allergy. J Allergy Clin Immunol. 1994; 94:70-6.

15. Ta V, Scott DR, Chin WK, Wineinger NE, Kelso JM, White AA. Differential skin test reactivity to pollens in pollen food allergy syndrome versus allergic rhinitis. Alergy Asthma Proc. 2015; 36: 379-85. 


\section{APJAI}

16. Anhoej C, Backer V, Nolte H. Diagnostic evaluation of grass- and birch -allergic patients with oral allergy syndrome. Allergy. 2001; 56: 548-52.

17. Skypala IJ, Calderon MA, Leeds AR, Emery P, Till SJ, Durham SR. Development and validation of a structured questionnaire for the diagnosis of oral allergy syndrome in subjects with seasonal allergic rhinitis during the UK birch pollen season. Clin Exp Allergy. 2011; 41:1001-11.
18. Pastorello EA, Ortolani C, Farioli L, Pravettoni V, Ispano M, Borga A, et al. Allergenic cross-reactivity among peach, apricot, plum and cherry in patients with oral allergy syndrome: An in vivo and in vitro study. J Allergy Clin Immunol. 1994; 94: 699-707. 